\title{
CULTURAL ISSUES IN NEGOTIATIONS BETWEEN AN AMERICAN MANAGER AND AN ARAB COUNTERPART
}

ALEXANDER NIKOLAJ SEMERAD

This paper aims to critically discuss and analyse the cultural issues that can be anticipated when an American manager plans to negotiate with an Arab counterpart. First, the importance of understanding the cultural differences in a business environment will be emphasized. Secondly, the cultural issues that can be anticipated with regards to the negotiation process will be highlighted followed by the issues in communication between both parties. Fourthly, other considerations are developed. Lastly conclusions will be drawn. The frameworks and models discussed in this paper are well intended to highlight cultural issues, however several aspects limit their accurateness and applicability. Therefore, further considerations should be taken into account, as the literature stereotype might not always reflect reality. 


\section{CULTURAL DIFFERENCES}

According to Tylor (1958) culture is "the complex which includes knowledge, belief, art, morals, law, custom, and any other capabilities and habits acquired by man as a member of society". In the business environment, cultural differences go beyond eating habits or greeting forms during the first encounter. Culture shapes behaviour as indicated by the Spanish philosopher José Ortega y Gasset (1914) with his statement "I am I and my circumstances". Culture even influences the perception (Berlin and Kay, 1969; Adelson, 2005) and neural activity (Han and Northoff, 2008).

\section{With the emergence of international and intercontinental organisations, the need for understanding cultural differences, but also how to overcome these gains more weight, as it is the key point for success.}

The first step to plan a negotiation is to get familiar with the counterpart's culture. According to Amber er Hovey (2007) and Seib (2005), the definition of what constitutes the "Arab identify" is arguable. These authors link the Arab identify to the Arab League, a regional organisation of 22 Arab countries. The Arab League itself (1946, cited in Sabry, 2012) defined Arab as "a person whose language is Arabic, who lives in an Arabic-speaking country, and who is in sympathy with the aspirations of the Arabic-speaking peoples".

According to Saee (2008), negotiation is a process in which two or more parties communicate with the purpose of reaching a joint agreement regarding different ideas or needs. Saee (2008) continues stating that negotiation becomes cross-cultural when the involved parties have a different cultural background, hence do not share the same way of thinking, feeling, and behaving. To proceed with the analysis, the United States and Saudi Arabia are chosen as examples to illustrate cultural issues that need to be anticipated if negotiation is to be successful. The reason behind the selection is based on the fact that Saudi Arabia represents an opportunity for US organisations to do business with, being a major investor in the US (Zahra, 2011) and is ranked under the top 20 of host economies for FDI inflows (Khakhar and Rammal, 2013).

The importance of cultural awareness lies in fact that, according to Gelfand and Brett (2014), dissimilarity in values and beliefs results in difficulty for individuals to find a common frame of reference. To begin with creating this common ground as well as overcoming these dissimilarities, Hofstede's cultural dimensions can be used to assess the cultural differences between the US and Saudi Arabia, which are visualised in Figure 1:

The United Stated scored a relatively low power distance and therefore is more egalitarian; whereas Saudi Arabia is a hierarchical society. In terms of negotiations, Samovar et al. (2009) states that the US selects members based on their competitiveness, verbal abilities and persuasive skills regardless of their position in the company. On the other hand, in Saudi Arabia the status of the negotiator is highly valuable, and the inclusion of high-ranking officers is an indication of seriousness and might not accept an American opponent under his status. Therefore, the US organisation must plan ahead which member(s) shall be involved in the negotiation process in order to match the status of the counterpart.

With regards to the second dimension, the US is highly individualistic where the level of commitment corresponds to the perceived benefit. In this sense, the US manager will approach the negotiation as a zerosum game with the aim to attain a suitable agreement, whereas the Saudi Arabian counterpart, being part of a collectivist society, will seek for equilibrium with a mutually satisfying agreement (Brett, 2000). Additionally, Lewicki et al. (2010) points out that collectivist negotiators focus more on long-term goals than individualists. 


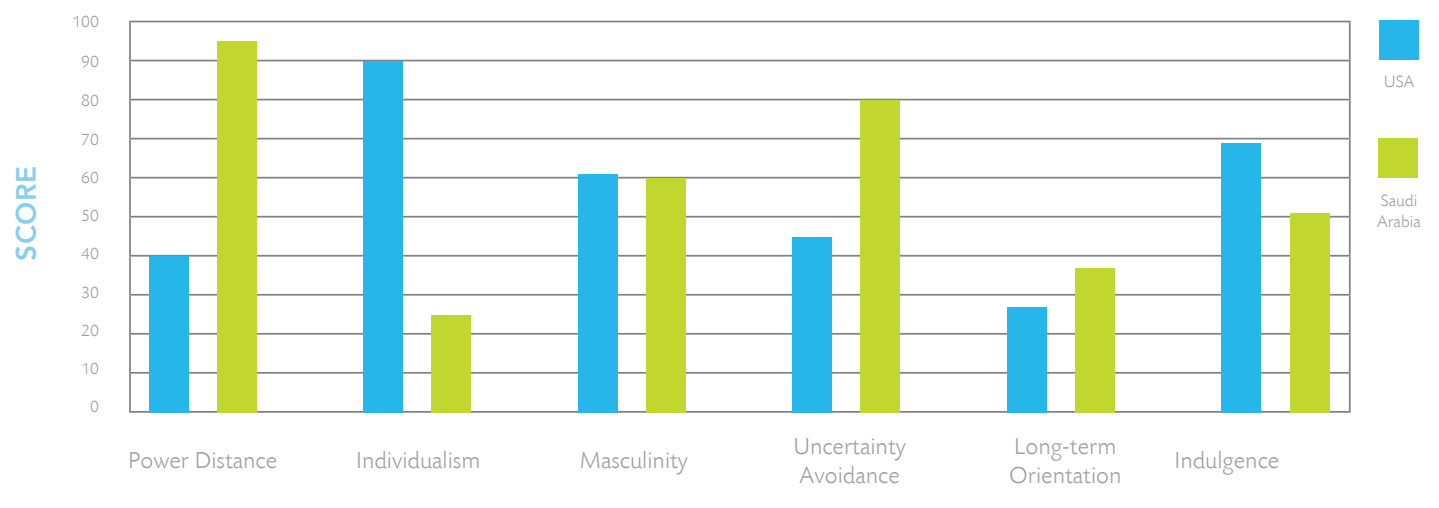

CULTURAL DIMENSIONS

Figure 1: Cultural differences between

USA and Saudi Arabia.

Even if both countries score high with regards to the masculinity score and are therefore driven by competition and success, in other words, to live to work (Kessler, 2010), the American manager must anticipate entering long-term commitment. This translates into the necessity to select business partners carefully according to the long-term vision and goals of the US company. To accommodate the views from both cultures, the American manager might propose to establish short-term milestones that lead to the long-term goal.

With regards to uncertainty avoidance, the US scored below average and accepts new ideas and is willing to try some new or different concepts.

\section{Nevertheless, Saudi Arabia has a high preference for avoiding uncertainty and maintains rigid codes of belief and behaviour. Change is repulsed or only embraced slowly.}

Therefore, ambiguity should be mitigated and risks should be addressed which require a thoroughly preparation. Lastly, Saudi Arabians exhibit great respect for their traditions and are normative in their thinking. The US had a similar low score in terms of Hofstede's et al. (2010) long-term orientation and therefore maintains some links with its own past. This may be a source of friction, as each manager might persist to implement his or her own traditions.

Even if Hofstede et al. (2010) relies on the law of big numbers, it should be noted that the territorial boundaries that constitute a country do not imply that all individuals residing within it are homogenous and share the same culture as reflected in the different minorities such as the Kurds, Berbers, Bedouins, Circassians, etc. Furthermore, according to Nasif et al. (1991), cross-cultural research is based on an ethnocentric pattern and represents only a single timeframe, in this case, between 1967 and 1973 (Hofstede et al., 2010) and therefore might be out-dated. This criticism is reflected in the recent event where South Sudan declared independence from Sudan (Taylor, 2014), but did not seek Arab League Membership (Sudan Tribune, 2014) as they have a different cultural identify. Additionally, the scores are not or only partially based on empirical data and are derived from data representing similar countries (Hofstede et al., 2010). These differences are highlighted in an Alkailani (2012) article that replicated Hofstede's study particularly for Jordan's culture and found similarities but also notable discrepancies. This indicates that Hofstede's findings might be relevant to anticipate some issues between cultures; however, it must be considered carefully as the culture might have progressed and values might have changed. 


\section{NEGOTIATIONS}

To further relate culture with negotiation, the steps of the negotiation process themselves have to be taken into consideration. According to Graham (1987), there are 4 steps of negotiation. The first step, non-task sounding, involves activities that are not related to the actual business. According to Graham and Hernández-Requejo (2008), Americans trust until proven otherwise which is reflected in a short non-task sounding process characterised by the statement time is money. On the other hand, Saudi Arabians rely more on strong relationships where trust must be earned before hand, indicating that they have a polychronic nature (Hall, 1981). According to Trompenaars and Hampden-Turner (1997), Saudi Arabia is a diffuse culture where they overlap work and personal life. In this sense, the American manager must show great patience and not rush into the second or third step of the negotiation, as common in US intracultural negotiations. Furthermore, Trompenaars and Hampden-Turner (1997) reveal that Saudi Arabia is a synchronic culture, where they engage in more than one activity, and appointments and schedules are subordinate to relationships.

Consequently, the American manager, but also the organisation he or she represents, must anticipate that the negotiations might be time consuming. Furthermore, the meeting should be planned between Salat times. For non-Muslim Americans, the prayer times can be found on the local newspapers such as the English Saudi Gazette (2015). Jeanette and Chaney (2012) state that during the encounter topics such as politics, religion, and family should be avoided, as they could be perceived as controversial or inappropriate, and as stated before, the key is to create a relationship and build trust, not discomfort. Furthermore, according to North and Tripp (2006), corporate gifts such as quality pens or business card cases can be handed over (with the right hand), but opulent gifts should be avoided as it may be interpreted as bribery. If a gift is offered to the American, it should not be rejected, as the Saudi counterpart will lose face.

The task-related exchange of information describes the exchange of information that defines the participants' needs and expectations (Doole and Lowe, 2008). Graham and Hernández-Requejo (2009) state that US managers tend to propose the topic and explain the reasons behind their requests only if necessary. On the other hand, Ali (2008) notes that Saudi Arabians address the whole subject with the need to understand their counterparts' demands, concerns, and needs. The Saudi Arabian polychronic nature is also reflected at this stage of the negotiation process, where the different points to negotiate about such as quantity or price are discussed in a holistic approach at the end, whereas Americans prefer to follow a linear sequence which is used by them to mark progress (Graham and Hernández-Requejo, 2008). Based on these findings, the American manager must re-orient his negotiation skills to provide all the information first followed by the agreements on the different points at the end.

With regards to persuasion, it is the parties' attempt to modify one another's standpoint. Americans are direct and start bargaining at a price close to what they expect to achieve; but nevertheless they are extreme in their offers and are more susceptible to competitive judgement biases, such as fixed pie bias (Gelfand and Christakopoulou, 1999) and self-serving bias (Gelfand et al., 2002). On the other hand, as Hendon et al. (1996) notes, for Saudi Arabians, bargaining is meant to establish relationships built on a mutual perception of virtue, honesty, and personal merit. Furthermore, Saudi Arabians set the initial offer high, but do not expect straight acceptance. According to Chaney and Martin (1995), the differences in bargaining between the countries are highlighted by the deviation of the offers, where the Americans negotiation point is off by 5 to $10 \%$ of the goal whereas Arab countries start much higher, such as 20 to $50 \%$ of the goal. In this sense, the American manager should become familiar with the process of bargaining, its practice, but also its meaning to avoid irritation from both parties. 




(C) zouzou1/123RF.COM

Nevertheless, before using any persuasion tactic with regards to the bargaining offers, the negotiation issue must be assessed; whether the Saudi Arabian counterpart has diametrical or integrative preferences. According to Loschelder et al. (2014), when the first offer does not reveal information on compatible preferences, the sender will claim more value as recipients' judgments are anchored by the initial offer and counteroffers are assimilated to it. However, if the first offer conveys information on compatible preferences, the recipient can leverage this insight to extract additional concessions from the first mover. As Saudi Arabia is a collectivist culture (Hofstede et al., 2010; Trompenaars and Hampden-Turner, 1997), they view themselves as agents constrained by social obligations and place great emphasis on maintaining harmony, even with their counterparts (Leung, 1997 cited in Gunia et al., 2013), and it may be assumed that they are more inclined to take an integrative standpoint (Gelfand and Realo, 1999).

Khuri (1968) states that the length of the bargaining process is proportional to the value of the commodity. It offers an indirect cue to the American how much the Saudi Arabian counterpart is interested in the deal. Furthermore, the American manager needs to understand his counterparts' persuasion tactic, which is appealing on emotions to change direction and reach understanding (Ali, 2008). This Arab approach is also reflected in Trompenaars and Hampden-Turner's (1997) findings, labelling Saudi Arabia as an affective culture, whereas the US is rather neutral focusing on rational arguments and objective data. This might seem irritating for the American manager, as his counterpart might be considered aggressive and loud and less focused on the American's structured arguments. However, this should not be misinterpreted as a threat, but should rather seen as a positive signal of interest. 
In this sense, the American manager can plan ahead his strategy, which could include not being the first to make an offer as well as not being anchored to the counterpart's offer, using more on emotional arguments focusing on the benefits for both parties overcoming the zero-sum game mentality, and most importantly, to enlarge the bargaining process. It should be noted that Americans are part of an individualistic culture, independent from social groups and focus on the distribution of resources and use threats and warnings as a persuasion tactic. However, the effectiveness of the persuasion tactics is arguable and might result in threatening the relationship between the parties and in the loss of the trust and respect of the Saudi Arabian counterpart. However, the US manager must not only consider the counterpart as a member of a culture, but also as an individual. In this sense, different biases such as lossaversion (Kahneman and Tversky, 1979) can be used which seems not be culturally variable (Gelfand and Brett, 2004), as it is risen from hardwired features of the perceptual system rather than learned.

Lastly, concession and agreement is the culmination of the negotiation process. Where for Western countries a handshake implies that an agreement is reached, in Middle Eastern countries it just means that negotiations are just beginning (Hofstede, et al., 2010). This might result in a conflict where the misunderstanding by the American manager thinking that the deal is completed leads to disappointment by his counterpart as he is then feeling rushed. In fact, as Alon and Brett (2007) point out, Saudi Arabians allocate time for important decisions and rushing them would signal disrespect.

\section{INTERCULTURAL COMMUNICATION}

As Herbig and Kramer (1991) stated, international negotiations can last between 2 to 6 times longer than it would domestically. As the American manager needs to gain the Saudi Arabians' trust, communication is the medium to achieve it. Gelfand and Brett (2004) state that individuals in different cultures use different languages to conceptualise or frame negotiation. As the official language of the United States and Saudi Arabia are different, it is a source of confusion and misunderstandings. The Arab counterpart might speak English, but it must still decode the message and interpret the meaning. Even if both parties have an understanding of the English language, the interpretation based on their cultural background might differ such as in the case of the word compromise, which has a positive connotation for Americans whereas in other cultures it might be considered a sign of weakness (Al-Ghamdi, 1999). Furthermore, the Saudi Arabian party might not be agile in English that might result in cognitive strain, but feel uncomfortable to ask for clarification to maintain his face.

Additionally, based on Hall (1990), Saudi Arabia is a high-context culture where indirectness in communication is one of its defining characteristics. Saudi Arabians avoid directness, and disagreement will be expressed through circumlocution, ambiguity, and metaphors to avoid embarrassment (Cohen, 1990 cited in Nelson et al., 2002). In contrast, the United States is a low-context culture where the information is in the explicit code (words), but this approach would cause the Saudi Arabian to lose face and the negotiation would end in failure. Alternatively, the US counterpart needs to pay attention to the non-verbal cues decode the senders' "yes" correctly, as it could be interpreted as an indirect disagreement. Communication between parties is even more impaired by the illusion of transparency (Vorauer and Claude, 1998; Gelfand and Brett, 2004), where the negotiators tend to overestimate the extent to which others discern their internal states, intentions, and goals.

The American manager must show great patience in the negotiation process, and this also applies to communication. As Graham and Hernández-Requejo (2008) state, Americans feel uncomfortable with silence and they fill this silence with concessions or conversation with persuasive appeal seeking for reciprocity. This leads to expose too much information falling in a weaker position. 


\section{OTHER CONSIDERATIONS}

As the American manager is approaching the Saudi Arabian counterpart, the American might seem to be in a weaker position and therefore must adapt to the counterparts' culture. However, this must not always be the case. The experience each party has with the counterpart's culture shall be considered. Weiss (1994a) rejects the simplistic idea of "when in Rome, do as the Romans do" and offers different approaches depending on the negotiators familiarity with the counterparts' culture and vice versa:

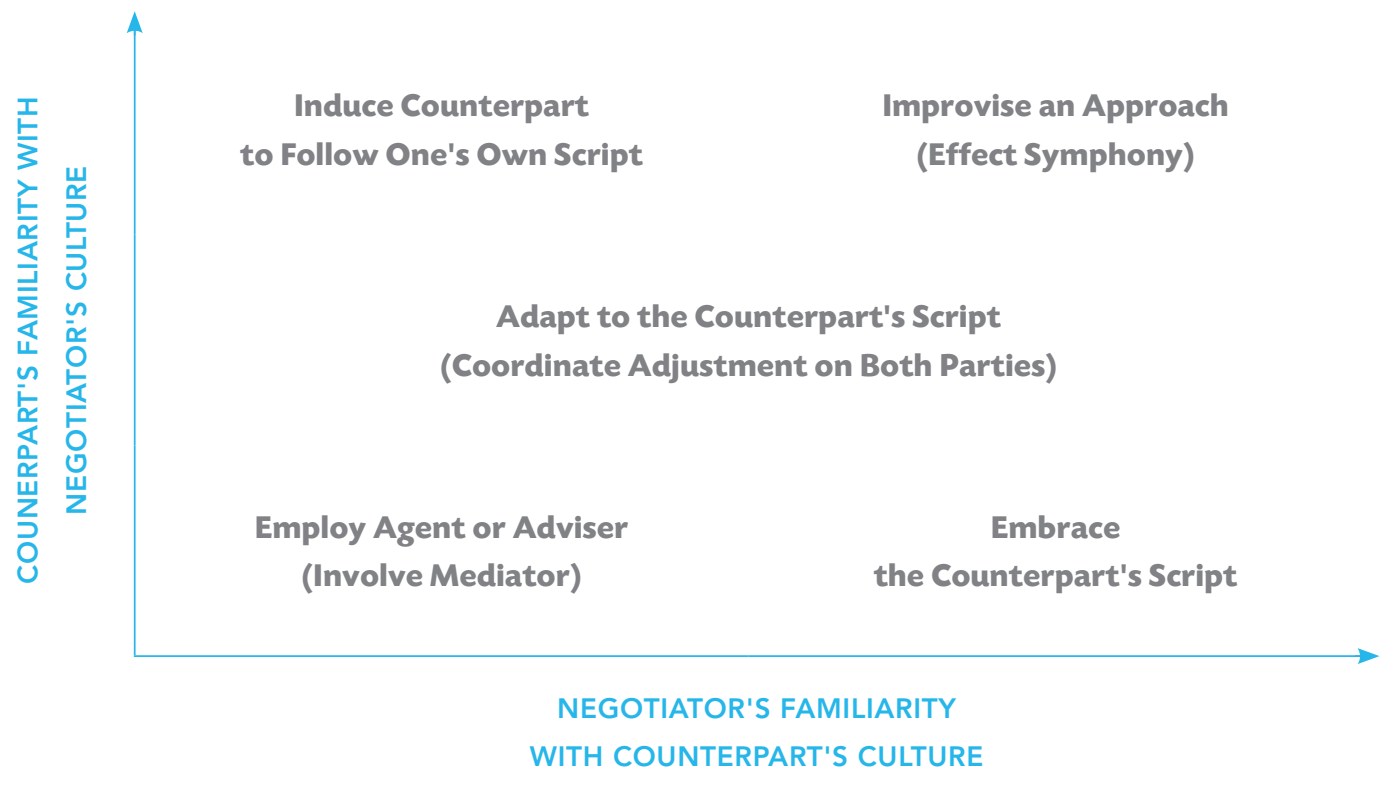

Brackets indicate a joint strategy, which requires

Figure 2: Culturally Responsive Strategies deliberate consultation with counterpart. At each level and their Feasibility.

of familiarity, a negotiator can consider feasible the

strategies designated at that level and any other level.

In this sense, if both parties are not familiar with each other's culture, Weiss (1994a) suggests to involve a mediator. However, if the Saudi Arabian counterpart is not familiar with the managers' culture, then the American manager must embrace the counterpart's script. In any case, Gelfand and Brett (2004) define adaptation an emergent process where parties interpret each other's goals and discover each other's style and begin to move in sync. Nevertheless, Weiss' (1994b) framework must be considered with regards to its fit with the counterpart's likely approach, its appropriateness, and its acceptability. Another factor to consider is whether the culture is tight or loose. As Livermore (2009) states, Saudi Arabia is a rather tight culture, having strong norms and a low tolerance of deviant behaviour. On the other hand, Adler and Graham (1989) report that American negotiators appear to be rather obstinate where their behaviour remained consistent in crosscultural situations only making few adjustments.

This constitutes a highly potential source of friction and indicates that in the process of anticipating cultural issues in cross-cultural negotiations it is not enough to examine the counterparts' culture, but also review and their own culture. The American manager must be aware of his own actions and for example must overcome the fix-pie bias (Gelfand and Brett, 2014) which is not biologically rooted but is culturally based. As Pinkley and Northcraft (1994) reveal, American negotiators maintain a win-lose standpoint, even after the provided information by the counterpart indicates that the interested are not diametrically opposed. 
In any case, both parties must know to which extent they are willing to adapt, without violating his or her own deeply imbedded cultural norms and values. For the purpose of concluding the negotiations successfully, Moore and Woodrow's (2010) strategic approaches, based on the willingness to adapt, can be taken into consideration:

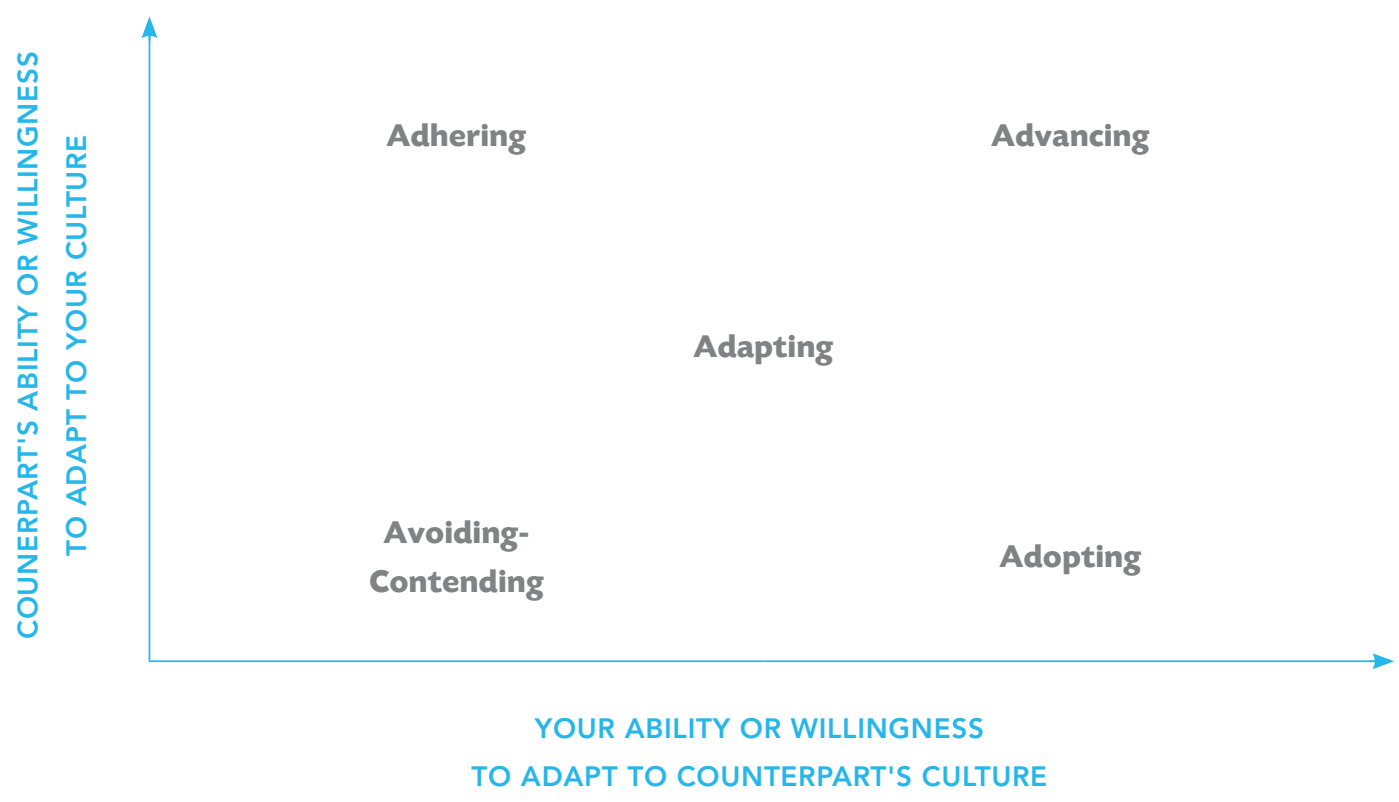

Figure 3: Strategic Approaches

As the negotiation process with Saudi Arabians involves building trust, the avoiding/contending strategy might not be the best option. On the other hand, both parties are part of normative cultures (Hofstede et al., 2010) which might prevent adoption of the advancing strategy. Therefore, either an adhering, adapting, or adopting strategy might be pursued. The appropriateness depends on the willingness of both parties to adapt. Therefore, the negotiators responsibility is to anticipate the likelihood of the counterpart's willingness to adapt.

The influence of the organisational culture must also be considered. The organisational culture might be used by the American manager as a common ground to start the negotiation, but as Sasaki and Yoshikawa (2014) highlight, it depends on the strength of the internal and external embeddedness. In this sense, the cultural issues that may arise if the American manager makes the wrong assumptions and fails to recognise the differences or similarities between the headquarters' and the subsidiary's culture. In fact, Sasaki and Yoshikawa (2014) identify 4 different interactions between organisations and intranational regions, namely integration, assimilation, separation, and marginalisation.

However, theory and praxis might not always meet. Taking into account the different variables that influence an individual apart from culture, it might be advisable to anticipate for events that are not supported by the stereotype of the literature. The American manager may use the culture of the Saudi Arabian together with the literature as a starting point, but shall consider the counterpart not only as part of a culture, but also as an individual. After all, the American manger must observe, evaluate, and adapt to any deviations. 


\section{CONCLUSION}

The culture between an American manager and a Saudi Arabian counterpart is in several aspects different, which complicate the finding of a common ground to proceed with the negotiations. Different findings by Hofstede et al. (2010), Trompenaars and Hampden-Turner (1997), and Hall (1990), which highlight characteristics of the individual cultures, can be used to anticipate the potential cultural issues that might surface during the process.

Based on these findings, the American manager must anticipate a time-consuming negotiation with the aim to maintain harmony and face, where threats and warnings are not effective but mutually benefitial for both parties. If negotiations have a successful result, the US manager will eventually commit to a long-term relationship. Communication must be interpreted by taking into consideration the paralanguage and nonverbal cues in the frame of the Saudi Arabian culture, rather than the meaning of the words of the sender.

Furthermore, models by Weiss (1994) and Moore and Woodrow (2010) address what strategies can be used taking into account the counterparts' actions with regards to the familiarity of the opponents' culture and willingness to adapt. Also the organisational culture must be reviewed to identify potential common ground, but also differences between the headquarters and the subsidiary. However, reality might not mirror what the US manager prepared for, and therefore he or she must, after all, observe, evaluate, and adapt to any deviations to achieve an agreement. Finally, cultural awareness does not only refer to examining the counterpart's culture, but also to review its own culture as well, including its weaknesses and strengths.

\section{REFERENCES}

Adelson, R. (2005) 'Hues and views: A cross-cultural study reveals how language shapes color perception', American Psychological Association, 36 (2), pp. 26.

Adler, N. and Graham, J. (1989) 'Cross-Cultural Interaction: The International Comparison Fallacy?', Journal of International Business Studies, 20 (3), pp. 515 - 537.

Al-Ghamdi, S. (1999) 'Success and Failure in Saudi-American Negotiations: American Views', International Negotiation, 4, pp. 23 - 26.

Ali, A. (2009) Business and Management Environment in Saudi Arabia. New York: Routledge.

Alkailani, M. (2012) 'Replicating Hofstede in Jordan: Ungeneralized, Reevaluating the Jordanian Culture', International Business Research, 5 (4), pp. $71-80$.

Alon, I. and Brett, J. (2007) 'Perceptions of Time and Their Impact on Negotiations in the Arabic-Speaking Islamic World', Negotiation Journal, 23, pp. 55 - 73.

Amer, M. and Hovey, J. (2007) 'Socio-demographic Differences in Acculturation and Mental Health for a Sample of 2nd Generation/Early Immigrant Arab Americans', Journal of Immigrant and Minority Health, 9 (4), pp. 335 - 347.

Berlin, B. and Kay, P. (1999) Basic Color Terms. Standford: Center for the Study of Language and Information.

Brett, J. (2000) 'Culture and Negotiation', International Journal of Psychology, 35 (2), pp. 97 - 104.

Chaney, L. and Martin, J. (1995) Intercultural Business Communication. Upper Saddle River, NY: Prentice Hall.

Doole, I. and Lowe, R. (2008) International Marketing Strategy. London: Cengage Learning.

Graham, J. L. (1987) 'A Theory of Interorganizational Negotiations', Research in Marketing, 9, pp. 163 - 183.

Graham, J. L. and Hernández-Requejo, W. (2008) Global Negotiation. New York: Palgrave Macmillan.

Gelfand, M. and Brett (2004) The Handbook of Negotiation and Culture. Standford: Standford University Press.

Gelfand, M. and Christakopoulou, S. (1999) 'Culture and Negotiator Cognition: Judgment Accuracy and Negotiation Processes in Individualistic and Collectivistic Cultures', Organizational Behavior and Human Decision Processes, 79 (3), pp. 248 - 269.

Gelfand, M., Higgins, M., Nishii, L., Raver, J., Dominguez, A., Murakami, F., Yamaguchi, S. and Toyama, M. (2002) 'Culture and egocentric biases of fairness in conflict and negotiation', Journal of Applied Psychology, 87 (5), pp. 833 - 845. 
Gelfand, M. J. and Realo, A. (1999). 'Individualist-collectivism and accountability in intergroup negotiations', Journal of Applied Psychology, 84, pp. 721-736.

Gunia, B., Swaab, R., Sivanathan, N. and Galinsky, A. (2013) 'The Remarkable Robustness of the First-Offer Effect: Across Culture, Power, and Issues', Psychology Bulletin, 39 (12), pp. 1547 - 1558.

Hall, E. T. (1981) Beyond culture. New York: Doubleday.

Han, S. and Northoff, G. (2008) 'Culture-sensitive neural substrates of human cognition: a transcultural neuroimaging approach', Nature Reviews Neuroscience, 9, pp. $646-654$.

Hendon, D., Hendon, A. and Herbig, P. (1996) Cross Cultural Business Negotiations. London: Greenwood Publishing Group. Hofstede, G., Hofstede, G. J., e Minkov, M. (2010) Cultures and organizations: Software of the mind. New York: McGraw-Hill . Kahneman, D., and Tversky, A. (1979) 'Prospect theory: An analysis of decision under risk' Econometrica, 47, pp. 263 - 291. Kessler, E. H. (2010) Management theory in action. New York: Palgrave Macmillan.

Khakhar, P. and Rammal, H. (2013) 'Culture and business networks: International business negotiations with Arab managers', International Business Review, 22, pp. 578 - 590

Khuri, F. (1968) 'The Etiquette of Bargaining in the Middle East', American Anthropologist, 70 (4), pp. 698 - 705.

Lewicki, R., Barry, B. and Saunders, M. (2011) Essentials of Negotiation. New York: McGraw-Hill/ Irwin.

Livermore, D. (2009) Leading with Cultural Intelligence. New York: American Management Association.

Loschelder, D., Swaab, R., Trötschel, R. and Galinsky, A. (2014) 'The First-Mover Disadvantage: The Folly of Revealing Compatible Preferences', Psychological Science, 25 (4), pp. 954 - 962.

Maritn, J. and Chaney, L. (2012) Global Business Etiquette. Santa Barbara: Praeger.

Moore, C. and Woodrow, P. (2010) Handbook of global and multicultural negotiation. San Francisco: Jossey-Bass.

\section{IMAGE LIST}

FIGURE 1: Hofstede, G., Hofstede, G. J. and Minkov, M. (2010) Cultures and organizations: Software of the mind. New York: McGraw-Hill.

FIGURE 2: Weiss, S. (1994a) 'Negotiating with "Romans" - Part 1', Sloan Management Review, 35 (2), p. 51.

FIGURE 3: Moore, C. and Woodrow, P. (2010) Handbook of Global and Multicultural Negotiation. San Francisco: Jossey-Bass. 